\title{
Críticas e Interpretaciones del Arte Pirandeliano
}

\author{
Por: Gaetano Foresta
}

$V i$ condurró sotto un velame antico a intender novo caso e nova pena. Chi nel giovine ch'io fingo sé vedesse, mesto occonsenta.

Esta es una de las notas juveniles de la personalidad pirandeliana que manifiesta la actitud simbólica dada por él a la poesía, $\mathrm{y}$ a los cuentos y al teatro y que encontramos, precisamente, en el librito de poesías juveniles que se titula "Mal giocondo".

He querido citarla no tanto porque en ella se encuentra, sintetizada poéticamente, una de las fórmulas comunes a su arte, sino para dar a los lectores la posibilidad de seguir al escritor en sus variadas manifestaciones, siendo la obra de Pirandello un problema aún no completamente cresulelto por $q_{a}$ Serítica.

Ha sido una temporada en nuestra vida vecina y, además, lejana por la profunda perspectiva que una terrible serie de acontecimientos compone, en la cual Pirandello dio nombre a todo nuestro afán, a nuestras humanas relaciones, a nuestra piedad.

Penetramos, entonces, en la obra pirandeliana como en un infierno de espejos y de sombras y salimos con desesperadas revelaciones, con alucinaciones lógicas hasta la obsesión. Después vinieron a tranquilizar esta primera tempestad los americanos y, desde entonces hasta ahora en que volvemos a leer a Pirandello, hemos bebido, como escribe Cardarelli, en otras fuentes.

El Pirandelismo que tan profundamente nos desbarató lo hemos visto disolverse bajo el punzante filo de la crítica, así que aquél proceso sofístico a nuestra realidad cotidiana logró aparecer como uña broma frente al proceso al que nos citaba Kafka.

Es la guerra la que crea las condiciones propicias para comprender a Pirandello. Son los hombres que vuelven de la guerra 
y que de modo convulso advierten el disolverse de su principio de identidad, la trágica desintegración del yo, el juego loco de espejos alrededor de su propia individualidad.

El horror, del que habían sido protagonistas la sangre, la mentira, la blasfemia, el íncubo, la obsesión; todo eso se ve ahora, en la conciencia, en el silencio de la paz.

Hay, también, el hecho de que nuestra cultura empieza, después de la guerra de 1914, a europeizarse, a librarse de todos sus ceñidores provinciales, a mirar con ojos, por cierto aún no agudos, lo que ocurre fuera; pero es, sobre todo, lo que ocurre en el corazón del hombre lo que constituye el patrimonio esencial de la obra de Pirandello.

En una Europa cómoda, tranquila, apenas sacudida por algún relámpago social, toda conmovida por los descubrimientos arqueológicos y por efectivos jubileos, Pirandello entrevió la feroz y grotesca máscara de un mundo enloquecido.

Algo muy parecido le ocurría a otro gran espíritu: el americano Edgar Lee Masters. Nadie hasta ahora ha pensado en el pirandelismo que hay en la "Spoon River Anthology" y ha observado qué pirandeliono infierno hay en las confesiones de aquellos muertos (1).

La trágica visión pirandeliana iba generándose como un presentimiento, anticipando una realidad que la guerra debía trágicamente manifestar en la conciencia de cada uno. - No parecerá, entonces, extraña la indiferencia que circundó la obra pirandeliana antes de la guerrap ini extrañará tampocoler hecho de que muchos críticos hayan rectificado su juicio, parcial o totalmente.

Durante un cuarto de siglo, Pirandello pasó sin ninguna atención por parte de la crítica militante. Después de la guerra, hay, en cambio, el descubrimiento frenético, entusiasta, apasionado.

De estudios profundos y superficiales sobre Pirandello no hay escasez y los críticos de Pirandello se dividirán, así, en dos categorías principales: Algunos dirán que en la obra pirandeliana hay filosofía y que, en consecuencia, el arte resulta comprometido; otros dirán que no hay filosofía y que el arte florece en ella con toda felicidad.

El representante más destacado del primer grupo es Benedetto Croce: él considera la manera, introducida por Pirandello, como motivos artísticos sofocados, oprimidos y alterados por un con-

(1) Sclascla, Leonardo. Pirandello e 11 Plrandellismo. Pág. 22. Edit. S. Slascla Caltanlssetta, 1953. 
vulso e incongruente filosofar. Siguiendo la estela de Croce, Luigi Russo rechaza casi toda la obra de Pirandello, por estar rellena de filosofía y consumida por la carcoma del pensamiento.

Galletti, Cremonte, Siciliano están convencidos de que su manera sentenciosa rebaja, en Pirandello, el tono de la virtud poética. Momigliano y Srntinio, aunque se muestran más abiertos a la consideración del arte pirandeliano, reconociendo que, a veces, entre la red de pensamientos, pasan también palpitaciones de vida y que en los cuentos se encierra una gran humanidad, concluyen, respectivamente, que los personajes, los movimientos, los motivos, el ambiente, el estilo, todo lleva una melancolía extraña, esquematizada con procedimientos demasiado intelectuales; que las excepcionales calidades inventivas y racionales del artista son, en suma, un límite a su arte, carente, muchas veces, de evidencia, de armonía, de tranquila y desinteresada contemplación.

Croce y los crocianos no cambiaron su juicio y, quizás el excesivo clamor impidió que ellos efectuasen un tranquilo examen.

Tilgher intuye cómo en lá obra de Pirandello iba a realizarse el lugar geométrico de toda la inquietud de la época, el drama del hombre del occidente.

La fórmula "vida-forma" que caracteriza de manera sintética y perspicaz el centro del mundo pirandeliano, el eje de la intuición pirandeliana de la vida, ligaba el caso Pirandello al nombre de Tilgher, quien, adaptandozalmundo de Pirandello la terminología filosófica dejGeorg Simmeb] involuntariamente, ponía el mundo pirandeliano en términos tan definitivos que Pirandello se vio como aprisionado en ellos.

Cuando Silvio D'Amico escribe que en el disolverse del principio de identidad, en este cambio de la personalidad humana en una fantasmagoría de sombras vanas, se descubría el núcleo ideal del arte de Pirandello, no está lejos de la interpretación de Tilgher: ¿qué son, pues las sombras vanas sino vanas formas, sino vida fulgurada e inflamada en formas?

Después de algunos años, inspirándose en un discurso de Bontempelli, estupendo y vivo discurso, en el cual llama candor este detenerse en un período de adolescencia, este grácil sentido de la tragedia de la vida, de la locura y de lo absurdo en que la vida se presenta frente a los ojos del adolescente, lo que es propio de la obra pirandeliana, de Benedetti, crítico que ha escrito sobre Pirandello las páginas más agudas y persuasivas, no hace sino sustituir al binomio vida-forma otro: criatura-personaje. 
A semejanza de una célebre definición que hace del univeIso kantiano una cadena de causalidades suspendida a un acto de libertad, pudiéramos resumir el universo pirandeliano como una cotidiana esclavitud en un mundo sin música, suspendido a una infinita posibilidad musical; a la intacta y satisfecha música del hombre solitario. La musical posibilidad de la criatura, el musical y libre fluir de la vida y la cotidiana esclavitud de la criatura que ha querido individualizarse como personaje, es decir, como forma.

Ha llegado el momento de citar a Gramsci y de acercarnos a su punto de vista. Es preciso tener en cuenta que él escribe en la cárcel. En aquel silersio físico que lo circunda y que llevaría a otros a la debilidad y a la desesperación, él llega a ser el hombre más libre, y, por ejlo, aquí se ve a Pirandello con libertad.

"En realidad no me parece dice él —que pueda atribuirse a Pirandello una concepción del mundo coherente y que pueda extraerse de su teatro una filosofía; por eso no se puede decir que el teatro pirandeliano sea filosófico.

Pero, ciertamente, en Pirandello hay motivos que se anudan de modo genérico a una concepción del mundo que puede ser definida como subjetiva. El problema, sin embargo, es éste: 1) ¿Estos motivos, están presentados de manera filosófica, o los personajes, en cambio, viven estos motivos como un modo individual de pensar? ¿La filosofía implícita es simplemente cultura y eticidad individual o sea existe, enire ciertos grados, al menos, un proceso de transfiguración artísticg en el teatro pirandeliano? "Más aún; ¿se trata de un reflejo siempre igual de carácter lógico o por el contrario las posiciones son siempre diferentes, o sea, de carácter fantástico? 2) ¿Estos motivos son necesariamente de origen libresco, culto, extraídos de los sistemas filosóficos individuales o existen en la vida misma, en la cultura del tiempo y también en la cultura popular, en el folklore? Este segundo aspecto me parece fundamental y puede ser resuelto, a través de un examen comparativo de los varios dramas, los escritos en dialecto, donde se representa una vida rústica, dialectal y aquellos escritos en lengua literaria, donde se representa una vida superdialectal de intelectuales burgueses de tipo nacional y también cosmopolita.

No es inoportuno citar también, entre los más conspicuos pensadores, .a don José Ortega y Gasset, en su ensayo: "La Deshumanización del arte", donde concretamente habla de Pirandello.

"No obstante sus tosquedades, dice él, y la vasteza continua de su materia, ha sido la obra de Pirandello, "Seis personajes en 
busca de autor", tal vez la única en este último thempo que provoca la meditación del aficionado a la estética del drama. Es ella un claro ejemplo de esa inversión del tema artístico que procuro distinguir. Nos propone el teatro tradicional que en sus personajes veamos personas y en los aspavientos de aquellos la expresión de un drama humano. Aquí, por el contrario, se logra interesarnos por unos personajes como tales personajes; es decir, como ideas o puros esquemas.

Cabría afirmar que es éste el primer drama de ideas, rigurosamente hablando, que se ha compuesto. Los que antes se llamaban así no eran tales dramas de ideas, sino dramas entre seudopersonas que simbolizaban ideas. Asistimos al drama real de unas ideas como tales, de unos fantasmas subjetivos que gesticulan en la mente de un autor. El intento de deshumanización es clarísimo y la posibilidad de lograrlo queda en este caso probada".

\section{EI ideal estético de Pircondello}

Pero, ¿cuál es el ideal estético de Pirandello? El arte, para Pirandello, no debe aislar una forma, aunque sea esencial, de la vida, prescindiendo de toda otra que se agita; sino que debe ser vida de ella misma. Vida, pues, y no, como interpreta Tilgher, espejo, representación de un choque, de una lucha que se sostendría con las formas del arfe.ca d.e Letras

Cristo, dice bien $\bar{a}$ este respectorMignosi, es un poco el sufrimiento de todas las criaturas pirandelianas, como fermento de rebelión y de elevación, como ímpetu tendido a desgarrar aquel capullo de carne y de prejuicios que viste nuestra alma. ¡Alma, vida, tiene que ser el arte. ¿Y qué es la vida? Hay dos modos de mirar a la vida: uno antiguo o abstracto; el otro moderno o concreto. A la luz del primero, la vida aparece toda como un lago, sereno y transparente, donde ningún soplo de viento viene a encrespar y mucho menos a turbar la sosegada superficie de las aguas. Hoy, como ayer, mañana como hoy; es el principio de la identidad. A la luz de la segunda manera, en cambio, la vida no aparece diversa de una hoguera encendida, que arde continuamente y sin cesar. Todo cambia, diría Epicarmo, y a causa de la naturaleza nunca se queda en el mismo modo $y$, cambiando, lo que cambia se transforma todavía; es el principio de la contradicción.

Cada cosa es y no es al mismo tiempo, es ella misma y su contrario al mismo tiempo. Lo bello es también lo feo, la verdad 
es también el error, lo bueno es también lo malo; el conejo es también león; don Abondio tiene su parte de coraje y Sancho Panza su parte de astucia. La naturaleza no ofrece los tipos puros; pero nos da tipos impuros, quiere decir mixtos de bien y de mal, de bello y de feo, como hace con el oro, con el azufre que nunca se nos presentan libres de material inútil. Las vicisitudes ordinarias, la materialidad de la vida, en suma, así varia y complicada, contradicen a las simples acciones ideales.

Ențonces, ni el trágico ni el comediógrafo son los que captan la vida en su sentido íntimo y real, sino, simplemente, el humorista. El, en vez de detenerse a mitad del camino para coger de la vida simplemente el aspecto cómico o simplemente el trágico, entiende que no puede tratar de un aspecto sin tratar del otro. Cada hecho, aunque doloroso, lleva en sí, si se le mira atentamente, una parte de ridículo.

El humorista lo examina, lo mira desde el interior, lo descompone $\mathrm{y}$, frente a aquello que era el aspecto cómico, ve surgir el aspecto trágico y viceversa; el humorista, afirma Pirandello, tiene el sentido de lo contrario y de lo opuesto; el humorista es, pues, la expresión más típica, más completa del arte y lo es porque de la vida coge su verdadera esencia: la dialéctica, o, lo que es lo mismo, los aspectos más diversos y completamente opuestos.

La forma con su sencillez es lo contrario de la vida con su! carácter dinámico y tortuosot. Hay que remover la forma, animarla de manera que siga a la vidg y' se adecue a ella; esto es lo que es necesario: el milagro de Pigmalión. Hacer que renuncie a su peso, a su corporeidad; que se aligere, que se perfeccione hasta confundirse con el alma que se agita en el interior. Es la lucha contra la materia, contra lo que más hace sentir su resistencia, su necesidad. De la escultura a la poesía libre, no sobrecargada por el sonido de las palabras y hecha simplemente de imágenes, este es el sueño de Pirandello. La imagen, inmaterial, móvil, varia, capaz de ayudar a interpretar la vida en todos sus aspectos, éste es el ideal de Pirandello. El color, la plasticidad, a los cuales tanta importancia han atribuido los artistas, en todo tiempo, no interesan a Pirandello. Apagan la llama de la vida, la cierran en una campana de vidrioopara conservarla luminosa, derecha; pero le quitan el oxígeno del cual necesita para continuar viviendo efectivamente. 


\section{El material artístico de Pirandello}

Si, para acercarnos a un autor, a la inteligencia de su obra, es útil por un lado conocer su ideal estético, por otro lado no es menos útil analizar su material artístico. El uno y el otro no se identifican con la producción artística, pero no se puede negar que en la base y como condición del hecho artístico están las impresiones, las experiencias que el novelista, el comediógrafo ha recibido durante su existencia y sobre todo durante los años en que el alma es más apta, por su limpieza, para captar las impresiones que le ofrece el mundo subjetivo y el extrasubjetivo.

Pues bien, ¿cuál es el combustible del que se inflama el arte de Pirandello? ¿Cuáles son los elementos que más concurren a formarla? Para alcanzar este conocimiento hay que ir al nacimiento, a los años que Pirandello transcurre con su familia en la villa de Caos y en Porta Empedocle.

Sicilia desde hace poco tiempo ha sido sustraída a los Borbones y ya el pequeño Luigi empieza a dar los primeros pasos, a leer en la cara de su padre y de su madre los primeros signos, a intuir sus sentimientos. La liberación de la isla está aún en su recuerdo, en los discursos de todos, especialmente en los de su madre. A los trece años, junto con sus familiares, ella había debido alejarse de la patria, irse a Malta, donde su padre había sido desterrado, a causa de ciertas foesías-politicas que habían hecho recaer sobre él las Jsospechas del conspiradorrso"

Luigi respira con el primer aire esta época. Aquí se encontrarán los gérmenes que darán vida a la obra: "Viejos y jóvenes".

Símbolo de amor, de abnegación es la madre; él la recordará en los años más difíciles, cuando durante la primera guerra mundial se encuentra en Roma. Del padre no conserva una imagen indeleble. Ocupado en los trabajos de la mina, con los obreros, con los socios, Esteban no tiene tiempo para inclinarse hasta Luigino, para mirarle a los ojos, para ver la luz que resplandece en su alma.

La madre, no: le comprende, le sigue, le facilita el camino. Espíritu abierto, ánimo dulce es el de la señora Pirandello. El marido es duro. La madre, quizás, predispon e el corazón del hijo, aún niño, a una actividad amable hacia la mujer, y lo impulsa a crear aquellos tipos femeninos de tan rara bondad y delicadeza. Para ninguna de las mujeres que él creará tendrá palabras de reproche, tampoco para aquellas que parecen, -como Agata Renni, 
Ersilia Drei, La Ignota, la señora Morli, Lina Marnis, doña Livia, Marta Ayala, la señorita Caporal, Ana Verónica, Leonora Barli, etc.,-- las más culpables, las más ligeras; tampoco para aquellas que se manifiestan, -como Livia Frezzi, la señora Carvalena-, las más egoístas o las más opresivas.

Además de su familia, Girgenti contribuirá a formar los atavíos de sus creaciones artísticas: situada frente al mar, frente a la tierra soleada de Africa, la ciudad, aquella del siglo pasado, está toda dividida por calles y callejuelas que suben, bajan, dan vueltas sin que nunca desemboquen en una plaza, en una calle ancha que las recoja todas como en un colector. Por esas calles, hombres, de caras tristes, asombrados, caminan de prisa, sin mirarse. Cada uno para sí. Solos por las calles, solos en casa, donde las mujeres nunca reciben el dulce encanto de una sonrisa, de una mirada. El orgullo personal los une y el mismo orgullo personal los separa.

Las mujeres, por las calles, no se miran sino por el deseo íntimo de superarse recíprocamente; los hombres, si se encuentran, lo hacen para poner en claro algo, para hacer que prevalezca su propio punto de vista, su opinión, su propia doctrina. Hablan, se interrumpen el uno al otro, gesticulan, se desasosiegan, giran con sus frases, con su lógica, como giran las calles de su ciudad.

Es porque no conservan a Grecia como un signo exterior en los templos o en otras huellas sino que la llevan en la sangre.

Como langostas que invaden un campo y lo pueblan, estos hombres entran con sus imágenes en la cámara öscura del ánimo de Pirandello, enriquecen de figuras, de tipos que, más tarde, aún transplantados a otros lugares, aún vestidos o disfrazados como empleados del ministerio, como artistas cinematográficos, representarán el motivo humano, dramático de sus cuentos o de sus comedias. Ciaula, Rico Verri, doña Mimma, Saru Argentu, Micuccio, Quaqueo, Marcantonio Rovi, Perazzetti, Mariagrazia, Antonio Serra, etc., todos llevan las marcas, las características de la gente de Agrigento: son imaginativos, tristes, porfiados, celosos, razonadores.

Así, sea que viva en Roma, sea que viva en Alemania, en América, en París, Pirandello permanece ligado a su tierra: Te sempre vedo, sempre da lontano (1), con el corazón, con la imaginación, para esbozar el esquema de sus creaciones.

(1) (Ritorno - in Zampogna - Sociedad ed. Dante Alighieri Roma 1911, pág. 109). 
De mayor relieve, por los reflejos que producirán en el mundo artístico de Pirandello, es la estancia en Alemania y precisamente en Bonn. No tanto por sus estudios de filología, cuanto por sus relaciones con la rubia Yenny: a ella Pirandello dedicará una colección de versos "Pascua de Gea"; de ella tendrá el más cariñoso recuerdo:

\author{
E tu, Yenny? Ti sei rimosto dietro \\ la tenda? Piangi? \\ Eh, tu, dottor, lassú donde t'ho tratto, \\ ree promesse ripeti olla gentile \\ compogno
}

Un recuerdo que él guarda en su memoria. Satisface a su necesidad de amor la rubia Yenny, como la filosofía alemana satisface a su tendencia a la abstracción, al razonamiento.

El idealismo, combatido por el realismo, por el positivismo, volvía, aunque molestado por el existencialismo, a Alemania. $\mathrm{Pi}-$ randello lo respira con el aire, lo asimila. Frente a sus ojos el idealismo deviene relativismo; algo que roza la posición de Gorgia; deviene fatiga de investigaciones, lucha entre lo que las cosas son y lo que nosotros las hacemos; deviene incomprensión recíproca que nos ahonda en la soledad más escuálida, que nos hace perder la confianza en huestra conciencia, el sentida de nuestra individualidad para dispersgrnos en un mundo indeterminado de un yo, sin cara ni carácter, para echarnos a la discreción de eso o aquello, de cuantos son los sujetos que entran en relación con nosotros y que se forman una idea cualquiera de nuestro ser personal.

¿Crees ser uno, estar firme en tu personalidad; no ser ninguna otra alma más que aquella que has encontrado en un momento de tu vida?, no: eres muchos, tantos, cuantas son tus posibilidades de ser, uno con éste, uno con aquel; cada día, cada instante, siempre nuevo, siempre diferente. Eres tantos tú y son tantos otros los que entran en relación contigo, siempre nuevos, siempre diferentes, también ellos, de momento en momento.

Así, estás convencido de que eres uno $y$, en cambio, eres dos, como Esteban Giogli o la señora Morli; eres cien mil y por eso ninguno, como Vitangelo Moscarda.

Materia de drama, de comedia es el idealismo para Pirandello; materia de arte. Esto es lo que para él constituye la filosofía. 
Es la filosofía, contra la cual los críticos han protestado tanto, la que da un sentido de humanidad a los personajes pirandelianos; a causa de la filosofía, de la razón de que se sirven y tienen que servirse, se escapan de su ferocidad.

\section{La producción artística en relación a los problemas que Pirandello ha intentado resolver}

Descubierta la fórmula que individualiza el teatro de Pirandello, a través del panorama de la crítica más reciente, examinando el material artístico, será fácil comprender cómo el mundo de Pirandello está hecho, podemos decir, concéntricamente: se desarrolla y se enriquece, en el tiempo, elaborando núcleos originarios que en su conciencia están siendo desde siempre y de vez en cuando surgen. Lo que ocurre en la evolución del tiempo es la liberación de la afición, cuando ha llegado a tal intensidad, como hecho fantástico, y a tal madurez, como hecho de conciencia, para que siga la fuerza clarificadora y comunicadora de la expresión.

Así, se puede encontrar también la manera de agrupar la producción artística alrededor de los problemas que el artista ha intentado resolver: la teoría del personaje, puesta por la intensidad y, diríamos, por la misma prepotencia de la actividad creadora sometida al vigoroso rigor de una encendida reflexión. Aquella teoría que interesa a cualquier posible problema del personaje con relación al autor, oa la intexpretación teatrab y al público, encuentra su manifestación en la trilogía que el mismo Pirandello llama 'la trilogía del teatro': "Seis personajes en busca de autor", "Cada uno a su manera", "Esta noche se actúa improvisando".

Esta trilogía, depende' en cierto modo, de otra gran obra: "Los gigantes de la montaña", donde se ve la ideal exigencia de la auto-representación del personaje. Los seis personajes, como tema crítico-estético, representan la voluntad del personaje de alejarse desde la matriz creadora y de llegar a la realidad, a su realidad dramática; al mismo tiempo, atestigua la necesidad del medio de manifestación, sin el cual el personaje cae. En suma, queda implícito que la expresión, la forma, la ejecución, la técnica, no son elementos extrínsecos, adjuntos al hecho creativo, sino parte integrante, esencial, del mismo fenómeno artístico, determinado en sus exigencias.

Idéntico problema estético se refleja, aunque bajo diferente luz, en: "Esta noche se actúa improvisando". 
Después del personaje del yo se encuentra, en la obra pirandeliana, otro personaje, más confuso y más perfectamente infeliz: el hombre que vio su propia existencia $\circ$ sea, el problema de la personalidad.

Ha visto su propia vida, pero no con sus ojos. Ha visto su vida con los ojos ajenos, en tantas maneras diversas, absurdas e insospechadas por él, cuantos eran los que lo veían. En la novela "Uno, ninguno y cien mil", los numerosos motivos sobre el problema de la personalidad, esparcidos en la obra de Pirandello, son recogidos y concentrados en esta novela que tiene como en el antecedente inmediato el cuento: "Esteban Giglio uno y dos". El mismo problema está esbozado en: "La señora Morli una y dos".

Aparte del juicio estético, queda aclarado que "Uno, ninguno y cien mil" es la obra más significativa para el conocimiento del problema de la personalidad que obsesionó a Pirandello.

Pirandello ha escrito el cuento "Soplo", donde hay la revelación del concepto de la vida, trágico, grotesco: un hombre ha descubierto en el simple soplo de sus labios el poder de dar la muerte, y, aburrido de la humanidad y del vano agitarse de quien es inconsciente y obtusa marioneta de sí mismo, exasperado también, cuando se acerca a la cama del pobre niño enfermo, de la piedad - la piedad tan incapaz de confortar la vida- se va, con una pasión feroz y alegre, como si la suya fuera una justicia, se va recorriendo las calles de una ciudad, soplando y sembrando la muerte. Corre y Jcorre, incrédulal désunpodeo y feliz, hasta que se encuentra fuera de la ciudad, en un campo florecido. Allí, parándose, tímido, sorprendido, deslumbrado, detiene el soplo frente a una dulce jovencita, ignorante, sentada en medio de una pradera: ¿no sería ella, quizá, la imagen de la vida, sola, ahora, joven, sobre la tierra?

Y ha escrito "Una jornada", maravillosa interpretación lírica de una vida, donde un hombre se halla, al quebrar la noche, arrojado de un tren en marcha, en la estación de una ciudad desconocida. Vaga y vaga por la ciudad y mientras parece que los otros saben también lo que hacen y por qué lo hacen, él no sabe nada de sí ni de los otros, suspendido en una incertidumbre tímida, malhumorada y maravillada al mismo tiempo. "¿Es posible que yo haya crecido tanto, quedándome siempre como un niño y que no haya hecho nada? Habrá trabajado, sí, todos parece que lo saben y lo honran por eso. Ha trabajado, sí, pero como en sueños, como si él hubiera permanecido dentro de sí aún tan foven. 
Había vivido y la jornada llegaba al fin y la bellísima, la misteriosa, la ignota, la vida había huído; él lo había visto en sueños, con su corazón joven, al final de aquella larga jornada en la que trabajando mucho, pero casi sin darse cuenta, había envejecido".

La bellísima, la misteriosa, la ignota, la ignorada, la vida. No, aquella que, aunque triste, enamora, sino la bella que encanta y enamora desde lejos, jdesde muy lejos! Es la ignota de "Como tú me quieres"; es Fulvia de "Como antes mejor que antes"; es Delia Morello de "Cada uno a su manera"; es la Nestoroff de "Los cuadernos de Serafina Jubio", también la pobre pequeña Ersilia Drei de "Vestir a los desnudos". Y todas son la ignota; también Donata de "Encontrarse"; también la Tuda de "Diana y la Tuda"; también Veroccia de "Cuando eres alguien". Y todas son la vida; la vida que es bella y desconsolada, buena y mala a la vez. tierna y cruel, sin descanso, sin tregua, siempre en fuga; la vida que lleva consigo los instintos más despreciables y las pasiones más nobles, que todo lo conoce aunque se ignore a sí misma; la vida que queremos y que al mismo tiempo huimos, en el continuo tormento de su esencia mudable.

Entre sus personajes hay uno que Pirandello prefiere como tipo del hombre: es Conrado Selmi, en la novela "Los viejos y los jóvenes". El lo prefiere por contraste; porque no se le asemeja. Le gusta porque no se le parece. Su persistente juventud Conrado Selmi la debía al valor, ealapoquísimo valor que siempre había dado a la vidāor El no hábíal querido apesadumbrarla con demasiados recuerdos, demasiados escrúpulos, con aspiraciones tenaces, como hacen muchos a quienes, después, bajo tal carga, se les doblegan las piernas y se les encorvan las espaldas, jviajero sin maleta, Conrado Selmil También Pirandello dice de haber salido, echando por la borda todo rastro de fe y todo engaño. Sí; pero había una huella que no podía arrancar: lo que llevaba dentro de sí: la razón, el tormento de la razón y aquella necesidad de buscar apasionadamente, con afán, un "por-qué", aunque desesperadamente convencido de que un "por-qué" no existe - de que, al menos, no se puede encontrar.

La divina adhesión a la vida de algunas criaturas, nunca ligadas a nadie, admira y envidia Pirandello en Conrado Selmi. Es el tipo de hombre que a Pirandello le hubiera gustado ser; el que realiza todas sus nostalgias, porque no conoce los vanos tormentos de su espíritu y el vago, atroz aislamiento del quedarse mirando a los demás. Pirandello es trágicamente serio y profundamente. 
honesto para parecerse a un Conrado Selmi; pero tiene, éste, en la boca, el gusto de la vida, tan áspero y tan voluptuoso, que desea asemejársele. Viajero sin maleta que en cada lugar ha cogido el bien y consumido la nostalgia. El mundo de Pirandello está, en cambio, impregnado de toda nostalgia.

\section{El Pirandelismo}

Cerca de Pirandello más verdadero y original hay el pirandelismo, eso es, una manera, una mecanización de juego intelectual. El pirandelismo surge cuando el tema pirandeliano, el conflicto entre individuo y sociedad o en el mismo individuo, entre lo que parece y lo que es, entre la vida mudable y la forma fija, entre la vida sometida a la ley de la transitoria mutabilidad y el arte que quiere la ley de lo absoluto, no está iluminado por la pasión del escritor en el momento en que lo sufre.

Como pirandelismo puede definirse la falta de equilibrio por exceso o por defecto de uno de los factores de la concepción pirandeliana. Y muchas faltas de equilibrio pueden notarse, por ejemplo, en la solución trágica del Enrique IV, donde Enrique es asustado por la vida de su misma ficción que en un momento le ha empujado al delito, mientras la tragedia interior del personaje era más que suficiente al tema.

Una falta de equilibrio es evidentísima aún en el tercer acto de "Cuando eres alguienulic dondelila representación se disuelve en una repetición cansada del motivo principal. "Diana y la Tuda", especialmente en el diálogo del primer acto entre Sirio y Giuncano, cristaliza en una evidencia conceptual que es, después, absorbida por el intenso y patético calor dramático. También "Cada uno a su manera", en medio de un exceso de concentración, tiene extraños momentos donde los problemas apenas se plantean justaponténdose y no saliendo el uno del otro.

Es necesario buscar a Pirandello no sólo donde es menos característico, sino donde es más significativo y completo, desde el lado humano más que desde el punto de vista intelectual, es decir, en aquella compenetración de los elementos constitutivos de su espíritu sutil, de su alma humana.

"El gorro de cascabel" es una de las obras más perfectas del teatro menor; profunda, de una dolorosa humanidad y vibrarte al mismo tiempo. Interesante es, también, la figura de Ciampa, que acepta su desgracia con el mismo fatalismo con el que Tara- 
ra acepta la justicia, ésto es, como son, para el campo, las malas cosechas. .

Ciampa no puede evitar que la joven esposa le traicione y mucho menos que le traicione con su patrón; pero puede exigir también de parte de sus dueños, que la cosa no se haga pública, que, al menos, socialmente, su arte de marido sea respetado. Extraña, compleja y además singularmente cándida esta psicología: arraigada en el sentido del honor viril. Parece ofender a lo que llamamos la moral; sin embargo hay también un derecho moral, el derecho a que sea respetado el pudor de una desgracia. El contraste, entre el pobre hombre de buena fe y el mundo que quiere herirlo más de cuanto ya la vida, inevitablemente, lo hiere, surge desde este pudor juzgado cobardía.

También en "Piénsalo Jaimito" la dulce tolerancia y generosidad del profesor Toti es considerada como escandalosa aquiescencia a la inmoralidad o al menos a una escandalosa ingenuidad. Pero desde la cándida peroración del profesor Toti surge indirecta y $\sin$ embargo fuerte la acusación al mundo y a su manera de juz gar. "La vida que te di" forma parte ya, en cierto sentido, de aquel teatro pirandeliano que puede decirse es el más original, en el que el motivo sentimental colorea toda la trama en lucha con el motivo intelectual y psicológico, con insólita armonía.

\section{Ecos de humanidad en los cuentos de Pirandello "Jorge Puccinelli Converso"}

Pero donde más fácilmente Pirandello atrae nuestra atención es en los "Cuentos para un año", que tan vecinos son al teatro por analogía de situaciones. Es, aquí, donde sin duda se manifiesta la libertad fantástica y creativa fuera de la cristalización a la cual se habíu sometido en muchas comedias. Es, aquí, donde Pirandello, libre de todas las preocupaciones filosóficas, libre de la angustia de la fórmula, muestra su verdadera cara, se deja dominar por su inspiración creativa, lozana y nativa; y es, aquí, sobre todo, donde se puede coger, a través de los medios de ana instintiva simpatía, uno de los aspectos más vivos de aquel sistema de valores que se encuentran en la consistencia ideal del arte pirandeliano y que, sin ser definidos, tienen el privilegio de hacer irresistiblemente comunicativo y cotidiano el arte del escritor y de revelarnos mucha parte de aquel secreto que está en la conclusión del enrojecido fondo del drama de la vida del artista y del que él nos 
ha advertido con la insistencia de sus llamamientos al sentido de la humanidad.

Dejando, entonices, la acusación de cerebralismo, de inverosímil, de artificio; dejando los varios juicios de la erudita crítica literaria que parece se haya sentido provocada, como escribe Mignosi, por la perilla y la sonrisa de Pirandello, a'llegar a la lucha y a enojarse con las oscuridades dialécticas y con el examen de instintos de apologética filosófica, quiero subrayar, en el tormento que expresa, en la grave atmósfera de sus obras, en el fondo de la disolución aparente, en la triste nache de la realidad trivial y fangosa, en este abismo en el cual el artista se ha caído, la pequeña llama que gradualmente deviene luz y se revela: la llama de su humanidad, ésto es, de su bondad.

"Mi arte está lleno de compasión para todos aquellos que se engañan", así escribe Pirandello en 1910.

"Yo escucho a todos con sosiego". Como hombre, Pirandello cree en las cosas de las que no ve el sentido o el fin; pero de las cuales lleva en sí las necesidades; Cree en la bondad, en la justicia, en el heroísmo, en el ideal. Por estas razones cree aún también en el mísero hombre, mísero si no puede tener las cosas que necesita, si no puede comprender el sentido de las cosas que lleva consigo y las ve continuamente contrariadas, fustigadas, burladas por la vida.

Así, cargado comócestá de un disgusto violento hacia este juego de la vida firandello fija sobre los hombres su desesperado deseo de comprenderlos. Su deseo de comprenderlos es la forma de amor de Pirandello hacia los hombres. Amor despechado y triste, que tiene como objeto al hombre mucho más digno de compasión que los otros seres, porque está más golpeado por esta absurda máquina de la vida. Es por este motivo que, cuando el autor determina el choque entre los personajes y el alma, entonces, la ola de humanidad invade a los actores, de tal modo que devienen, imprevistamente, criaturas de carne y de sangre; y palabras que quiebran el alma y desgarran el corazón salen de sus labios. Por ello, cerca de las zonas muertas hay siempre unos momentos en los cuales el artista eleva su grito de humanidad. Por ésto las acusaciones adquieren una consistencia de sentido social y la desesperación, el afán, la náusea, el disgusto de la vida inútil, los detalles torvos y horrendos acaban refugiándose y confundiéndose en un sentimiento no expresado, pero elocuente y artísticamente grande: la bondad. Bondad que no es en Pirandello un 
nombre vano, sino simpatía hacia los justos, aunque derrotados. Bondad que es compasión e iluminada piedad; indulgencia de las Culpas y amor para las criaturas, inventadas por él.

Por aquel tono de confianza y de intimidad, por aquel carácter ambiental que los hace más comprensibles a nosotros, sicilianos, he querido hojear los "Cuentos para un año" y de ellos los que más tienen la virtud de comunicar el calor de su gran corazón, de sus sentimientos de amor para los humildes, de aquel sufrimiento que es leudo de rebelión y de elevación, lance tendido a rasgar, a desnudar de todo prejuicio nuestra alma, a considerar las llagas morales de la sociedad para confortarla con la suya y nuestra indulgencia.

En el fondo social, visto a través de la característica sonrisa pirandeliana, tan enigmática en la apariencia y tan profunda en significación, el motivo de la maternidad encuentra su más alta expresión, en el cuento: "Tarjeta roja"; el motivo de la instintiva fuerza de atracción hacia su propia criatura, en los cuentos: "El hijo cambiado" y en "El otro hijo"; el motivo del noble sacrificio comprendido y aceptado, en el cuento: "La nodriza".

Digna corona a este motivo de la maternidad pudiera ser, aunque indirectamente, el cuento tan famoso: "Piénsalo Jaimito".

Motivo altísimo que, a veces se eleva a motivo ascético, es el amor de Pirandello hacia los humildes. El ilumina la vida de los pobres de una luz superior de modo que sus criaturas, transfiguradas o desvirtuadas por el mal por el vicio, por la necesidad, presentan la cara de su propia humanidad vencedora y la fuerza del sentimiento hace que la misma voluntad teórica del autor se incline y que el artista se haga hombre y que llore y se conmueva, ofreciendo su ayuda para aliviar el espasmo de la tragedia humana.

En el cuento: "La mano del enfermo pobre", el autor nos introduce en un hospital, pero casi para prevenir al lector, se sirve de su bondad para decirnos que entre él y el hospital ha sabido siempre establecer dulces y delicadas relaciones. Pues del enfermo que tiene a su izquierda no ve otra cosa sino la mano; y él se pone a contemplar con amorosa curiosidad esta mano y escucha su fábula y de ella coge con cálido sentimiento la vida.

"Era la mano de un enfermo pobre; de la pobreza ella era la prueba ; algo sucio, que no es sucio propiamente en la mano de los pobres, sino casi la pátina de la miseria que ningún agua jamás quitará. Era la mano de un sastre". Pero no es ésto todo. El 
autor no se detiene ante el objeto exterior, quiere buscar y alcanzar la vida interior; pues es, sobre todo, esta ansiedad la que apasiona al artista. Y a aquella mano se anuda ahora el poema de la familia. "La mano, antes inerte, se alzaba con los dedos trémulos y casi vagaba sobre aquella rodilla... quizá, allí llegaba, a la rodilla, la cabeza de su niño y allí su mano acariciaba los cabellos mórbidos como la seda de aquella pequeña cabeza; miseria física y riqueza espiritual que concluye en un simbólico signo: un pequeño anillo que el enfermo llevaba en la mano. Si, algo también en aquel pequeño anillo anudaba: anudaba su nombre a la vida de su niño".

Veis como desde el episodio nos trasladamos al poema, como desde el limitado confín de un cuento nos recreamos de luz y de la intensidad de objetos y de sentimientos. Y para concluir, citaremos otros dos cuentos, que pertenecen también a este criterio de investigación de la personalidad humana de Pirandello, así como hemos intentado descubrirla: "El tren ha silbado" y "Ciaula descubre la luna". El uno y el otro tienen como protagonista dos labradores: en el primero el protagonista Belluca es un empleado, en el segundo, Ciaula, es minero. En el primero es la fuerza del espíritu la que viene a ser sometida; en el segundo la del cuerpo, pues el uno y el otro están, casi, embrutecidos por el trabajo; el uno y el otro no viven sino fuera del mundo.

"Sí; Belluca se habia 6lvidado desde hacía muchos años, olvidado completamente, de quie el imundoexistía. ¿Cómo no enloquecer frente a las condiciones de vida que el destino le había impuesto? Doce bocas a saciar, entre las cuales la esposa, la suegra y la hermana de la suegra, que eran ciegas, y todas ellas con el sueldo de copista. Absorto en el continuo tormento de aquella desgraciada existencia, como una bestia atada a la barra de una noria o de un molino, había olvidado que el mundo existia". Cuadro horripilante, dramático, por la conclusión a la cual conduce: Belluca en el silencio de la noche oye silbar el tren. El silbido del tren había desgarrado la miseria de todas sus horribles angustias y casi como desde un sepulcro descubierto se encontraba anhelante en el vacío airoso del mundo: Oh dulce vagar en el mundo lejano, en medio de la ciudad en la cual había vivido cuando era joven, entre las luces brillantes y el ritmo de una vida, vivida de diferente manera. Montañas solitarias, nevados .... oceános .... bosques. Todo esto veía detras del silbido del tren. El mundo ésto es, había regresado a su espíritu... se había embriagado, es- 
taba ebrio de aire y aparecía, ahora, a los ojos de sus compañeros, loco. Pero, Pirandello está allí, detrás de las palabras del compañero de Belluca, para cubrir con el velo delicado de la piedad y de la comprensión el triste caso de un delirante que nadie puede explicar, porque nadie sabe como este hombre ha vivido.

No menos conmovedor es el otro cuento en el cual Ciaula, obligado a vivir en las entrañas de la tierra, entre las tinieblas de las profundas cuevas, en las minas de azufre, una tarde, cuando salió al cielo raso, por primera vez, vio la luna; Igrande, plácida, como un sereno, luminoso océano de silencio, la lunal, jahora, ahora, de noche, saliendo de las entrañas de la tierra, él la descubría! ... Estático, cayó sobre su cargo, frente a la cueva. |Allí, allí estaba la luna, la lunal

¿Qué arte podría mejor que éste expresar el sentido social del carácter de Pirandello? El de Pirandello es un sentido de solidaridad $\mathrm{y}$ de confianza en lo humano, un sentirse siempre dentro de un orden vivo de socialidad.

En el vacío de la insensibilidad de los hombres, el tono de ternura y de piedad, la voluntad de relevar sus criaturas en un reverbero de bondad tiene el sonido de una consonancia, de un ritmo. Esta humanidad que se ve en el instante, en el gesto, en la descripción del ambiente, para coger los momentos del eterno mal y del eterno bien incesantemente en lucha, fija la condición del hombre que lucha contra el oscuro fondo de su esclavitud. Detrás del contenido del cuento, a veces humano, a veces supersticioso, a veces racional; detrás del grito, de la sonfisa," del humorismo, del aforismo, se puede, siempre, descubrir un surco indeleble que se trasmuda en dolor y en piedad hacia nuestra humanidad equivocada, disfrazada, ridiculizada. Y Pirandello está presente, bajo la cándida máscara de su serenidad, con la pena no sólo para sí mismo, sino para todas las cosas y todas las criaturas, como él las ve en la infinita ansiedad de su sentimiento que es sentimiento de amor y de piedad para el hombre.

Es necesario librar a Pirandello de todas las incrustaciones filosóficas y pseudo-filosóficas, de todas las etiquetas conceptuales, en una palabra del pirandelismo, restituir, en la crítica, a la obra pirandeliana aquella variedad, libertad, y efervescencia fantástica, que objetivamente posee. Ni Georg Simmel, ni Gorgia de Lentini. Nos encontramos con un corpus de obras fantásticas, de poesías nacidas de un estupor, ante el mundo, tan inmediato y de un encanto tan de una sistematización lógíca como el de Leopardi lírico. 
El candor del cual habla Bontempelli es la llave mejor para entender a Pirandello. La primera calidad de las almas cándidas es la incapacidad de aceptar los juicios ajenos y hacerlos propios. Bontempelli pronunciará un nombre, el nombre de un antiguo poeta, de un cándido poeta romano: Lucrecio. También Lucrecio muestra en la fachada de su obra una filosofía; pero también su filosofía es como un material aislante que le permite manejar el fuego blanco de su estupor, de su trágico y quebrantante estupor del mundo. Pirandello se asoma al mundo, descubre la vida como un teatro: totus mundus agit histrionem, la teatralidad de la vida que es precisamente un descubrimiento del alma cándida. Los hombres se afanan para parecer lo que no son y cada noche. en el silencio de sus habitaciones grises, prescinden de la máscara, se quitan los oropeles de la escena.

La tragedia está en el vivir, no en el morir. Está en el vivir cada día en los ojos de la gente. El ojo del mundo. Un inmenso ojo de cristal, abierto, ávido: la imagen que penetra dentro de este ojo se descompone, encuentra un delirante juego de espejos, pero monstruoso juego de deformaciones y de fugas. Y dentro del ojo del mundo entran las ceremonias de bodas y entierros, los bautismos, las viudedades, las rentas, las letras de cambio, los trajes, las crónicas del tribunal y de las alcobas. "Yo lo hago para el ojo del mundo". "Hágalo a lo menos para el ojo del mundo"l "Elige tu parte; cuida tu papel i el implacable ojo del mundo está fijo sobre tí; no creas que podrás escapar o evadirte de su campo visivo. Lo logró una vez, Vitangelo Moscarda, lo rogró Matías Pascal. Pero no siempre se logra, y aquel loco que creía ser Enrique IV de Alemania, sabio o loco, quiso engañar al mundo, cambiar el papel, erigirse en otro papel más cómodo para él. No jno se puede!

La campiña es estupenda, entre la ciudad enrojada, Girgenti, y el mar abierto. Es necesario ser hombres, solos, hombres solos, criaturas en Dios o en la naturaleza. Bajo un olivo sarraceno. mirar la campiña circundante, el mar, la ciudad, con sus pobres pequeños hombres. Sí, un antiguo olivo sarraceno. "Hay un olivo sarraceno, grande, en medio de la escena, con el que he resuelto todo". Quería decir Pirandello que había encontrado una solución escenográfica para "Los gigantes de la montaña". Y ya vecino a la muerte, en sus ojos, había un antiguo y gran olivo sarraceno.

Es éste el símbolo, el sello que puede imprimirse en su obra. Es el mejor modo para empezar a entender a un poeta" ${ }^{\prime \prime}$

(1) Sciacia - op. cit. págs. $81-83$ ). 


\section{BIBLIOGRAFIA}

A. TILGHER. - Studi sul teatro contemporaneo. Romo, 1928.

S. D'AMICO.- II Teotro itoliono. Milano, 1937.

S. D'AMICO.— Ideologio di Pirandello in "Comoedio". Novembre, 1927.

P. MIGNOSI. - II segreto di Pirondello. Milono, 1932.

M. BONTEMPELLI.- Pirondello, Leopordi, D'Annunzio. Milono, 1938.

B. CROCE. - Letteroturo dello Nuovo Italio, Vol. VI. Bori, 1945.

I. SICILIANO. - II teotro di Pirandello ovvero i fosti dell'ortificio. Torino, 1929.

L. SCIASCIA. - Pirandello e il Pirondellismo. Edit. S. Scioscio. Coltanissetto, , 1953.

F. PASINI.- Luigi Pirondello come mi pore.

F. NARDELLI.- L'uomo segreto: Vito e croci di Pirandello. Milano, 1932.

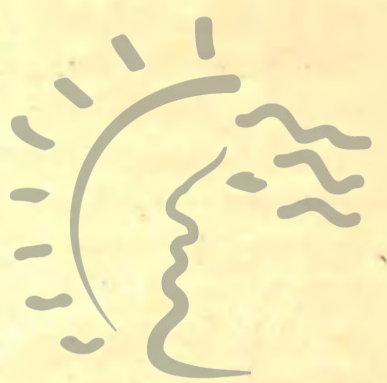

